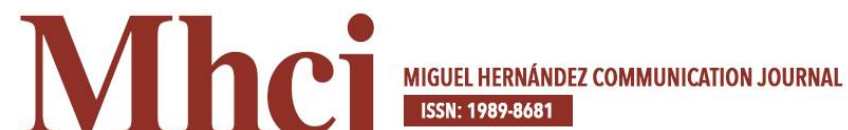

\section{Presentación sobre los estudios cinematográficos en la región latinoamericana (2000-2016)}

\section{Presentation on cinematographic studies in the Latin American region (2000-2016)}

Dr. Lauro José Zavala Alvarado| zavala38@hotmail.com

Universidad Autónoma Metropolitana - Xochimilco

A pesar de la presencia ubicua de la cultura de las pantallas y los medios audiovisuales en la sociedad contemporánea, los estudios cinematográficos en la región latinoamericana son todavía un terreno emergente, y están lejos de contar con el desarrollo que han alcanzado en países como España, Estados Unidos, Francia o Inglaterra.

Este monográfico de Miguel Hernández Communication Journal contiene un grupo de trabajos panorámicos sobre la investigación cinematográfica que se está realizando en 5 países de la región: Argentina, Brasil, Chile, México y Perú.

El elemento crucial para entender el desarrollo de este campo desde la perspectiva regional es la existencia de asociaciones de investigadores en los tres países que tienen mayor presencia cinematográfica y académica. Se trata de SOCINE en Brasil (1996), SEPANCINE en México (2005) y ASAECA en Argentina (2008). Desde su creación, cada una de estas asociaciones ha organizado encuentros internacionales de especialistas. 
Por su parte, SOCINE ha publicado las memorias de sus encuentros anuales, y cuenta con la revista Rebeca. ASAECA publica en línea la revista especializada Imagofagia. Y SEPANCINE ha publicado libros colectivos y números especiales de revistas universitarias. Estos encuentros y publicaciones han contribuido a dar consistencia y continuidad a la disciplina en la región, y tienen un efecto multiplicador que propicia la consolidación de una comunidad profesional.

Sin embargo, gran parte de la investigación sobre cine producida en la región latinoamericana se realiza a partir de iniciativas individuales, debido a que no existen todavía institutos de investigaciones cinematográficas que generen proyectos de trabajo colectivo.

En términos generales, durante los últimos 15 años la producción bibliográfica sobre cine ha tenido un crecimiento sostenido en la región, y coincide con la riqueza y diversificación del cine documental, y con el crecimiento exponencial de los festivales de cine en cada país.

En toda la región se observa un predominio de los estudios de carácter historiográfico, centrados en la cinematografía nacional. Esta producción cubre más de la tercera parte de la producción bibliográfica total de cada país.

También, como ocurre en todo el mundo, en cada país de la región se observa una explosión del interés de los investigadores por el estudio del cine documental. En Argentina, esto se refleja en la creación de la revista digital Cine Documental.

Por lo demás, el desarrollo de los estudios sobre cine es muy distinto en cada país. En las líneas siguientes se señalan algunos de estos rasgos distintivos. 
SOCINE, la asociación brasileña de investigadores de cine, es una de las más grandes del mundo, pues cuenta con más de 1,600 asociados. Desde el año 2000 publica un anuario que contiene una selección de las ponencias presentadas en su congreso, donde se puede observar que en los años recientes los investigadores más jóvenes empiezan a estudiar muchos temas que van más allá del cinema novo.

El Foro Brasileño de Enseñanza del Cine y el Audiovisual (FORCINE) registra más de 87 escuelas de nivel superior donde se enseña cine y audiovisual. Derivadas de estos programas, en 2014 se tenían registradas 730 tesis de maestría y doctorado sobre cine, de las cuales 500 están dedicadas al cine brasileño. Al mismo tiempo, es necesario destacar la existencia de muy distintos grupos de investigación. Por ejemplo, en la Universidad Federal de Bahía existe un Laboratorio de Análisis Fílmico (LAF) en el que participan los estudiantes de posgrado. En esa misma universidad se registra una producción de 12 libros colectivos de investigación sobre cine tan sólo en los últimos 3 años. Esto difícilmente ocurre en ningún otro país de la región.

También es notable, en Brasil, la traducción al portugués de libros de autores canónicos de teoría del cine, como Jacques Aumont, Robert Stam, Noël Carroll, Bill Nichols, Ann Kaplan y David Bordwell (del cual se han traducido 4 títulos). En 1983 y 2005 se publicaron distintas antologías de textos teóricos en traducción al portugués, con autores como Münsterberg, Bazin, Metz, Mulvey y muchos otros. En lengua española todavía no existe ninguna antología similar.

Por su parte, en Argentina se observa un interés muy marcado por los estudios sobre la memoria, la política y la historia, cuya interrelación domina el panorama de la investigación sobre historia del cine argentino, cine documental, Nuevo Cine Argentino y cine transnacional. 
También es notable en Argentina la existencia de numerosas revistas especializadas, como Otrocampo, Kilómetro 111, Toma Uno, Cine Documental, Imagofagia y Vivomatográficas (esta última dedicada al cine silente). Y es muy notable la existencia ---sin paralelo en el resto de la región latinoamericana--de colecciones de libros sobre cine publicados por numerosas editoriales con distribución nacional: Colihue, Manantial, Imago Mundi, La Marca, Libraria, Picnic y ENERC.

El congreso de ASAECA convoca cada 2 años a cerca de 400 investigadores y estudiantes interesados en el estudio del cine. El centro de toda esta actividad académica sigue estando en la Universidad de Buenos Aires (UBA).

La situación de la investigación sobre cine en México se define por la existencia de una separación muy marcada entre quienes tienen formación en ciencias sociales (especialmente historia, sociología y ciencia política) y los especialistas en disciplinas humanísticas (como estética, filosofía y semiótica). Durante el siglo XX predominó el estudio de la historia nacional a través del cine (y la historia canónica del cine nacional). Esta situación llevó a la creación en 2005 del Seminario Permanente de Teoría y Análisis Cinematográfico (SEPANCINE), formalizado en 2008. Esta iniciativa ha estimulado la creación de encuentros anuales de investigadores en media docena de universidades del país, incluyendo la Universidad Nacional (UNAM).

Por lo demás, al igual que en Brasil, durante los últimos 15 años se observa en México una diversificación de los objetos de investigación. Los temas recurrentes incluyen la relación del cine con el psicoanálisis y con estudios de género, educación, filosofía, semiótica, ética, ecología y derecho. Se registran 220 títulos de investigación sobre cine publicados de 2000 a 2016.

En Chile se publicaron, entre 2000 y 2009, un total de 59 libros sobre cine. Y en Perú se publicaron 99 libros entre 2000 y 2016. El 34\% de estos libros, 
como ocurre en el resto de la región, están dedicados a la historia del cine nacional.

En todos los países de la región existe la tendencia de las escuelas de cine y los programas universitarios de enseñanza del audiovisual de nivel superior a enfatizar la producción por encima de la teoría, el análisis, la historia y la crítica. Pero es necesario señalar que esto ocurre a contracorriente de las escuelas de cine que hay en Francia, Inglaterra, España, Estados Unidos y Canadá, donde la teoría y el análisis del lenguaje cinematográfico es anterior a la formación técnica.

En general, en todos los países de la región se observa un crecimiento exponencial de la bibliografía de los estudios sobre cine en lo que va del nuevo siglo. Es de esperarse que esta tendencia se mantenga y que propicie un diálogo entre los investigadores de los distintos países, lo cual a su vez podría propiciar la creación de redes internacionales, videotecas regionales y publicaciones conjuntas.

La investigación del cine en la región latinoamericana se encuentra en un momento de crecimiento y efervescencia, y este impulso podrá llevar, a largo plazo, a la producción de modelos teóricos de alcance universal.

Esperamos que la elaboración de este número de la revista $\mathbf{M H C J}$ contribuya a la construcción de este terreno emergente de la investigación interdisciplinaria. 


\section{(c) (1) () \\ BY SA \\ Licencia Creative Commons \\ Miguel Hernández Communication Journal \\ mhcj.es}

\section{Cómo citar este texto:}

Lauro Zavala Alvarado (2017): "Presentación sobre los estudios cinematográficos en la región latinoamericana (2000-2016)", en Miguel Hernández Communication Journal, nº, pp. 13 a 18 Universidad Miguel Hernández, UMH (Elche-Alicante). Recuperado el _ de de de 20_ de: [ink del artículo en mhjournal.org]

\section{How to cite this text:}

Lauro Zavala Alvarado (2017): "Presentation on cinematographic studies in the Latin American region (2000-2016)", en Miguel Hernández Communication Journal, n8, pp. 13 to 18 Universidad Miguel Hernández, UMH (Elche-Alicante). Accessed 20 _ in: [paper link in mhjournal.org] 